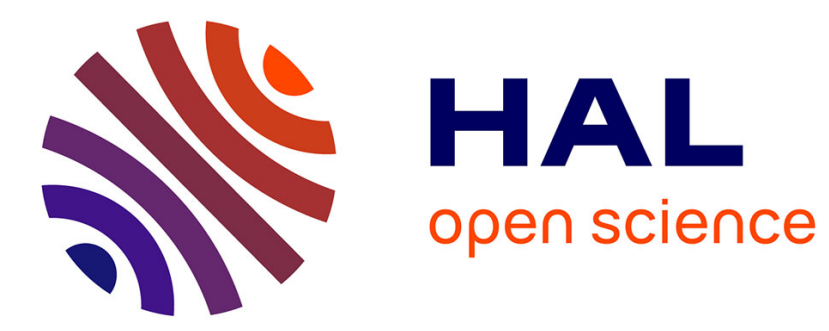

\title{
3D Computation of reactive moulding processes
}

Emmanuel Foudrinier, Cécile Venet, Luisa Silva

\section{To cite this version:}

Emmanuel Foudrinier, Cécile Venet, Luisa Silva. 3D Computation of reactive moulding processes. 11th ESAFORM Conference on Material Forming, Apr 2008, Lyon, France. pp.Pages 735-738, 10.1007/s12289-008-0280-0 . hal-00510337

\section{HAL Id: hal-00510337 \\ https://hal-mines-paristech.archives-ouvertes.fr/hal-00510337}

Submitted on 18 Aug 2010

HAL is a multi-disciplinary open access archive for the deposit and dissemination of scientific research documents, whether they are published or not. The documents may come from teaching and research institutions in France or abroad, or from public or private research centers.
L'archive ouverte pluridisciplinaire $\mathbf{H A L}$, est destinée au dépôt et à la diffusion de documents scientifiques de niveau recherche, publiés ou non, émanant des établissements d'enseignement et de recherche français ou étrangers, des laboratoires publics ou privés. 


\title{
3D Computation of reactive moulding processes
}

\author{
E. Foudrinier ${ }^{1}$, C. Venet $^{1}$, L. Silva ${ }^{2}$ \\ ${ }^{1}$ Schneider Electric - 37 Quai Paul Louis Merlin, 38000 Grenoble \\ URL:www.schneider-electric.com \\ e-mail:Emmanuel.foudrinier@schneider-electric.com; \\ Cecile.Venet@schneider-electric.com \\ ${ }^{2}$ Cemef, Ecole des Mines de Paris, UMR CNRS 7635 - BP207 Sophia Antipolis \\ URL: $\underline{w w w . c e m e f . e n s m p . f r} \quad$ e-mail: Luisa.Silva@ensmp.fr
}

\begin{abstract}
Electrical equipment for medium and high voltage is manufactured using reactive moulding process. During mould filling, air bubbles or weld-lines can appear which may be a huge problem for electrical insulation devices. Moreover, the use of thermoset materials induces delamination due to the resin's shrinkage. Product development delays can be reduced using numerical tools to simulate part forming process. In this paper, we present a three dimensional finite element analysis of the filling and curing stages of reactive moulding process. During the first stage, flow computation takes into account heat transfer and the curing reaction according to appropriate models. In the curing phase, the evolution of the degree of cure is coupled with an evolution model of the glass transition temperature. Taking in account his coupling phenomenon permits the computation of a more realistic curing kinetic and modelling of the slowdown at vitrification. The thermal field prediction is then more accurate. To validate this approach, experiments were performed. A comparison with computational results shows a good agreement in filling and temperature evolution inside the cavity.
\end{abstract}

Key words: Thermoset materials, Reactive Molding, 3D simulation

\section{INTRODUCTION}

Thermosetting materials are frequently used in electrical industry for their insulation properties. The specificity of these materials is that chemical reaction occurs during the forming process. This reaction influences all stages of the forming process because of its high interaction with rheological material properties $[1,2]$. Numerical simulations of the process will help understanding all phenomena that are taking place simultaneously. Due to the complexity of the produced parts (either thin or thick parts) a fully three dimensional approach is required. The purpose of this paper is the presentation and the validation of a new simulation tool which permits a realistic modelling of both filling and curing stage of the thermoset moulding process.

\subsection{General algorithm}

The whole moulding cycle is computed using a 3D finite element library based on tetrahedral unstructured mesh [3], used to develop the injection molding software Rem3 $\mathrm{D}^{\circledR}$ [7]. During the filling stage, the non stationary flow of the fluid is computed by solving successively conservation and transport equations, taking into account temperature and degree of cure influences. In the case of fibre reinforced thermosets a coupling with fibre orientation equation can be realized within the code [4]. For both filling and curing stages, heat transfer (due to mould conduction and exothermal curing reaction) and cure kinetics are solved. Finally, the influence of the material state (glass transition) on these phenomena is computed. An illustration of the general algorithm is given on figure 1 . 


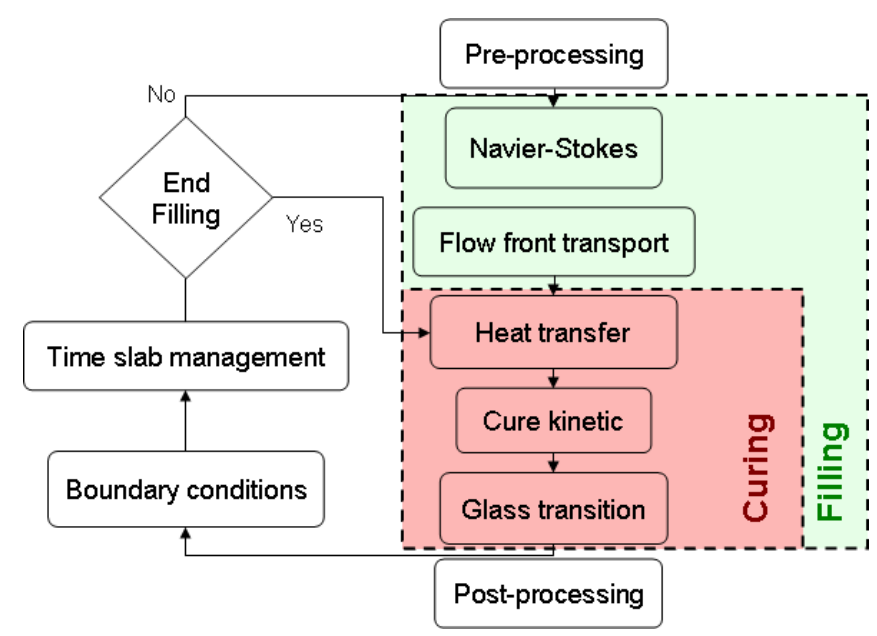

Fig. 1. General scheme of the thermoset module.

\subsection{General equations}

\section{2.a Flow computation}

We consider thermosets as incompressible viscous materials which flow inside the cavity following the Navier-Stokes equations (1):

$$
\begin{gathered}
\rho \frac{d v}{d t}-\nabla \cdot \sigma=\rho g \\
\frac{\partial \rho}{\partial t}+\rho \nabla \cdot v=0
\end{gathered}
$$

where $\eta=$ viscosity, $v=$ velocity, $p=$ pressure, $\rho=$ density and $g=$ gravity.

The viscosity depends on the strain rate tensor, the temperature and the degree of cure according to the following form (2):

$$
\eta=\eta(\dot{\bar{\gamma}}) f(T) g(\alpha)
$$

where $\gamma=$ shear rate, $T=$ temperature and $\alpha=$ degree of cure.

Dependence on the strain rate tensor is taken into account through purely viscous models [5], like for example the Carreau-Yasuda law (3):

$\eta(\dot{\bar{\gamma}})=\eta_{0}\left(1+\left(\frac{\eta_{0}}{\tau} \dot{\bar{\gamma}}\right)^{a}\right)^{\frac{m-1}{a}}$

where $\eta_{0}=$ plateau viscosity, $\tau=$ relaxation time, $a$ and $m=$ parameters adjusted to fit the shear-thinning behaviour.

The influence of temperature is governed by the Arrhenius law (4):

$$
f(T)=\exp \left(\frac{E_{a}}{R}\left(\frac{1}{T}-\frac{1}{T_{\text {ref }}}\right)\right)
$$

where $E_{a}=$ activation energy, $R=$ universal gas constant and $T_{r e f}=$ reference temperature.

The degree of cure implies a modification of the viscosity according to a percolation model (5):

$$
g(\alpha)=\left(\frac{\alpha_{g e l}-\alpha}{\alpha-\alpha_{g e l}}\right)^{C_{1}+C_{2} \alpha}
$$

where $\alpha_{\text {gel }}=$ degree of cure when gelation occurs and $C_{1}, C_{2}=$ constants.

During filling, the computational domain is subdivided in several subdomains. A VOF like function (6) gives us the position of the interface and allows computation of subdomains properties:

$$
1_{\Omega_{i}}(\mathbf{x}, t)=\left\{\begin{array}{lll}
1 & \text { if } & \mathbf{x} \in \Omega_{i} \\
0 & \text { if } & n o t
\end{array}\right.
$$

The evolution of the flow front is then known by solving the transport equation on the polymer's characteristic function (7):

$$
\frac{\partial 1_{\Omega_{f}}}{\partial t}+\mathbf{v} \cdot \nabla 1_{\Omega_{f}}=0
$$

\section{2.b Heat transfer equations}

The temperature balance equation accounts for the heat transfer due to conduction, the viscous dissipation and the heat released by the chemical reaction (function of the reaction kinetic):

$$
\rho C_{p} \frac{\partial T}{\partial t}=k \Delta T+\dot{\omega}+\Delta H_{\Sigma} \frac{d \alpha}{d t}
$$

where $C p=$ specific heat, $k=$ thermal conductivity and $\Delta H_{\Sigma}=$ total heat released by the reaction.

\section{2.c Cure kinetic}

The evolution of the degree of cure follows an unsteady state conservation equation (9):

$$
\frac{\partial \alpha}{\partial t}+v . \nabla \alpha=C_{k}
$$

where $C_{k}$ corresponds to a cure kinetic model as listed by Dimier [2]. Kamal \& Sourour model (10) is used in the present paper.

$C_{k}=\left(k_{1} \exp \left(\frac{E_{1}}{R T}\right)+k_{2} \exp \left(\frac{E_{2}}{R T}\right) \alpha^{m}\right)(1-\alpha)^{1-n}$

where $k_{i}=$ reaction constants, $E_{i}=$ activation energy, $m$ and $n=$ reaction exponents. 
The cure kinetic influences the glass transition temperature and can be taken into account using the Di Benedetto model [6] (11):

$T_{g}=T_{g}^{0}+\frac{\left(T_{g}^{1}-T_{g}^{0}\right) \lambda \alpha}{1-(1-\lambda) \alpha}$

where $T_{g}{ }^{0}, T_{g}{ }^{l}=$ glass transition temperature at zero and reference degree of cure and $\lambda=$ adjustable structure parameter.

\section{APPLICATION}

\subsection{Experimental set up}

After several benchmarks we test software predictions on a complex industrial application. Experiments consist in the over-moulding of an electrical part with an epoxy resin. Two flow conditions were investigated, a horizontal position and a $30^{\circ}$ inclination angle of the mold. The mold, heated at $120^{\circ} \mathrm{C}$, was filled by gravity at atmospheric pressure within $300 \mathrm{~s}$ with a standard epoxy-silica resin which initial temperature was $60^{\circ} \mathrm{C}$. In order to analyse the flow and to observe the evolution of the temperature, 8 thermocouples were introduced inside the cavity. Their positions are illustrated in figure 2. They were chosen for having a relevant observation on flow and on overheating.

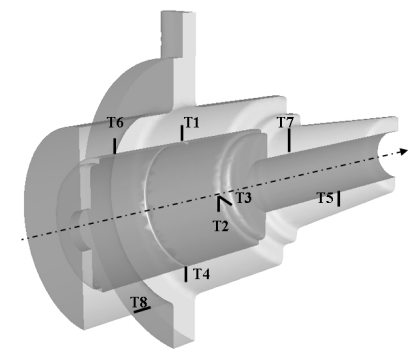

Fig. 2. Thermocouple positions inside the cavity

\subsection{Simulation data}

For having accurate simulation results in a reasonable computational time, we realized a $3 \mathrm{D}$ tetrahedral anisotropic mesh of the cavity as shown in figure 3. Initial and boundary conditions were chosen according to the experimental set up. Resin parameters are derived from Sekula \& al [7] characterization according to models described previously (Table 1). Moreover, due to the lack of consistent data concerning glass transition temperature evolution, it is consider as a constant. The mold wall temperature is fixed .

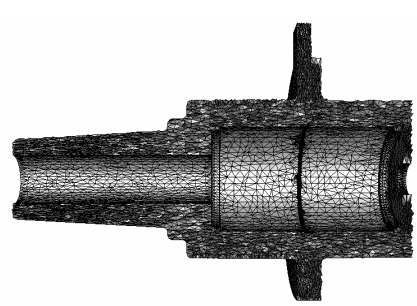

Fig. 3. Cutaway view of the mesh of the cavity (75593 nodes, 363579 tetrahedron).

Table1. Material data used

\begin{tabular}{ll}
\hline$\eta_{0}($ Pa.s $)$ & $1.13 \mathrm{e}-7$ \\
\hline $\mathrm{E}_{\mathrm{a}}(\mathrm{K})$ & 6026 \\
$\mathrm{~T}_{\text {ref }}(\mathrm{K})$ & 393.15 \\
\hline$\rho(\mathrm{kg} . \mathrm{m}-3)$ & 1885 \\
$\mathrm{Cp}(\mathrm{J} . \mathrm{K}-1)$ & 1040 \\
$\mathrm{k}(\mathrm{W} . \mathrm{K}-1)$ & 0.91 \\
\hline
\end{tabular}

\subsection{Numerical results}

\section{3.a Filling stage}

Figure 4 illustrates the accurate predictions of flow front position, in both conditions of molding angle, with experiments.
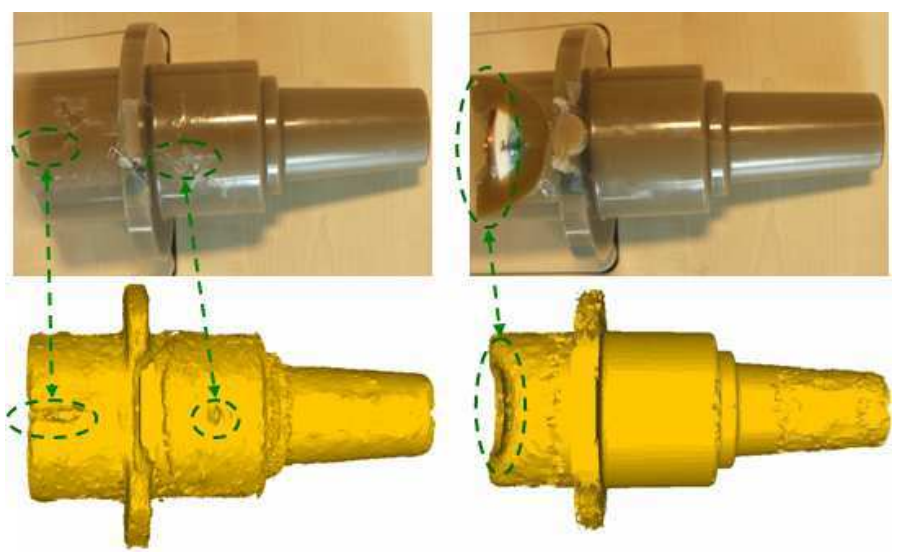

Fig. 4. Comparison of experimental end of fill positions and numerical predictions.

We then compare temperature measurements during filling, for the horizontal position of the mold, with the numerical predictions and we notice a good agreement. Some discrepancies are observed for thermocouples 4 and 8 which may be related to the decrease of the mold temperature during experimental filling. 

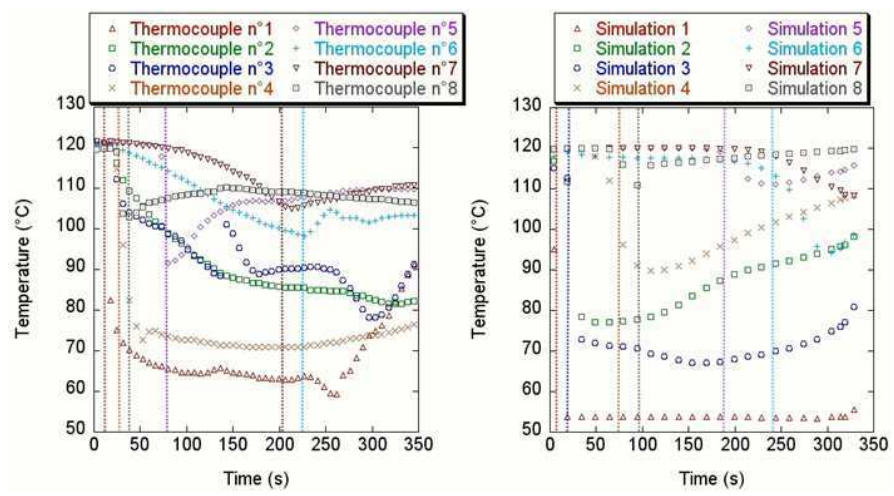

Fig. 5. Confrontation of experimental (left) and numerical (right) temperature on thermocouples during the filling stage.

\section{3.b Curing phase}

We can notice on figure 6 that numerical predictions slightly overestimate maximum temperatures during the curing stage. Furthermore, the maximum temperature arises faster in simulations. Material data used predict a too fast chemical reaction and this can explain difference on temperatures evolution. In order to perform more accurate predictions, we will account for a more accurate characterisation of material kinetic reaction.
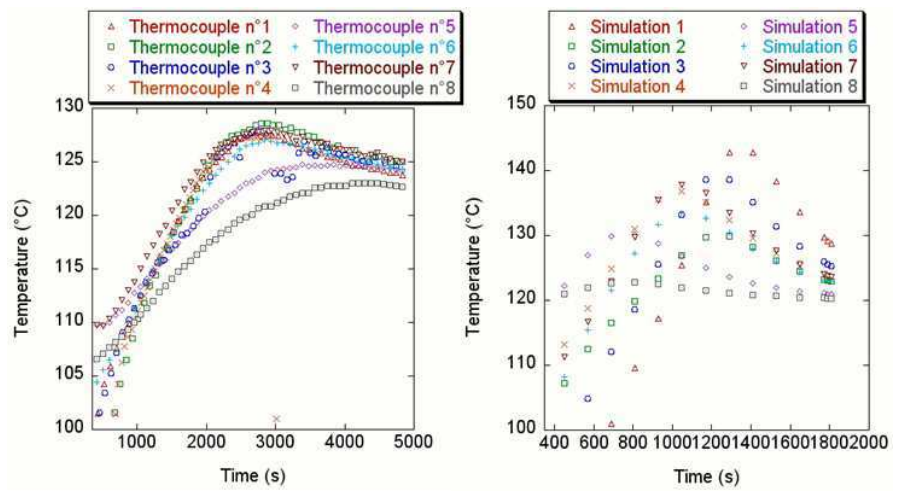

Fig. 6. Confrontation of experimental (left) and numerical (right) temperature on thermocouples during the filling stage.

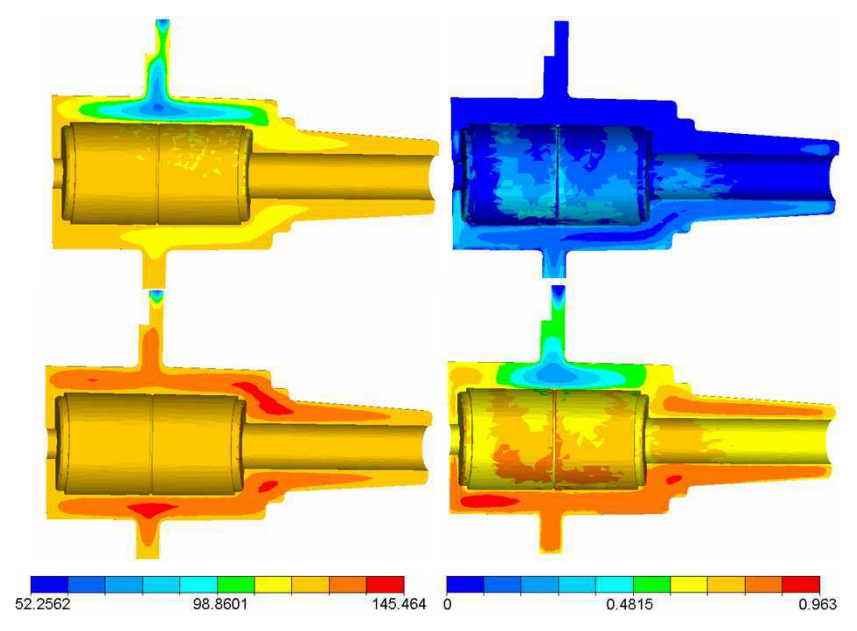

Fig. 7. Temperature $\left({ }^{\circ} \mathrm{C}\right)$ (left) and degree of cure (\%) (right) fields just after filling and after $700 \mathrm{~s}$
Figure 7 shows the correlation between the temperature and the degree of cure at the end of filling and after 700 seconds of curing. The part cures from bottom to top which permits shrinkage compensation. We can also notice that temperature maximum arise in thick regions of the part.

\section{CONCLUSIONS}

The reaction injection moulding software allows the accurate prediction of potential filling problems like air bubbles. The curing kinetics is well taken into account and provides the overheating prediction inside the cavity. However, we underline the importance of material kinetic reaction parameters characterization on the accuracy of the computed temperature field. Finally, this analysis should be extended to the computation of residual stresses induced by the cure. This work has been implemented as a thermoset module of the Rem3D ${ }^{\circledR}$ injection moulding software [8].

\section{REFERENCES}

1. P. Dumont, L. Orgéas, D. Favier, P. Pizette and C. Venet , Compression moulding of SMC: In situ experiments, modelling and simulation, Composites Part A: App. Sci. Manufacturing, 38(2), (2007), 353-368.

2. F. Dimier, Injection de systèmes réactifs : Détermination de lois cinétiques et rhéologiques et modélisation, Thèse de l'Ecole des Mines de Paris (2003)

3. H. Digonnet, L. Silva, T. Coupez, Cimlib: A Fully Parallel Application for Numerical Simulations Based On Components Assembly, In: Proceedings of the Int. Conf MATERIALS PROCESSING AND DESIGN, (2007) 269-274.

4. A. Redjeb, L. Silva, P. Laure, M. Vincent, T. Coupez, Numerical Simulation of Fibre Orientation in Injection Molding Process, In: Proceedings of the Polym. Proc. Soc. 21, Leipzig, (2005).

5. J.F. Agassant, P. Avenas, J.P. Sergent, B.Vergnes, and M. Vincent, La mise en forme des matières plastiques, Lavoisier Tec \& Doc, Paris (1996).

6. A.T. DiBenedetto, Prediction of the glass transition temperature of polymers: A model based on the principle of corresponding states, J. Polym. Sci., 25(9), (1987) 1949-1969

7. R. Sekula, P. Saj, T. Nowak, K. Kaczmarek, K. Forsman, A. Rautiainen, J. Grindling, 3-D Modeling Reactive Molding Processes : From Tool Development to Industrial Application, Advances in Polymer Technology, 22(1), (2003) 42-55..

8. L. Silva, C. Gruau, J.F. Agassant, T. Coupez, J. Mauffrey, Advanced Finite Element 3D Injection Molding, Intern. Polym. Proc., 3, (2005) 265-273. 